\title{
Fully bio-based, highly toughened and heat-resistant poly(L-lactide) ternary blends via dynamic vulcanization with poly(D-lactide) and unsaturated bioelastomer
}

\author{
Wan-Jie Si ${ }^{1}$, Xu-Pei An ${ }^{1}$, Jian-Bing Zeng ${ }^{1,2^{*}}$, Yu-Kun $\mathrm{Chen}^{2}$ and Yu-Zhong Wang ${ }^{3}$
}

\begin{abstract}
Inherent brittleness and low heat resistance are the two major obstacles that hinder the wide applications of poly(L-lactide) (PLLA). In this study, we report a fully biobased, highly toughened and heat-resistant PLLA ternary blend, which was prepared by dynamic vulcanization of PLLA with poly(D-lactide) (PDLA) and an unsaturated bioelastomer (UBE). The results indicated that during dynamic vulcanization PDLA cocrystallized with PLLA to form stereocomplex (SC) crystallites, which not only enhanced the molecular entanglement but also accelerated the crystallization rate of PLLA matrix. With increase in the content of PDLA, the matrix molecular entanglement increased while phase-separation was enhanced, which enabled the impact strength to increase first and then decrease. The ternary blends containing 10 wt.\% PDLA showed the highest impact strength. The presence of SC crystallites makes it possible to achieve a fully sustainable PLLA/VUB/PDLA ternary blend with highly crystalline matrix under conventional injection molding, due to the high nucleation efficiency of SC towards crystallization of PLLA. The highly crystalline ternary blend showed excellent heat resistance and better impact toughness than high impact polystyrene.
\end{abstract}

Keywords: poly(L-lactide), poly(D-lactide), dynamic vulcanization, toughness, heat resistance

\section{INTRODUCTION}

Bio-based polymers derived from renewable resources have attracted increasing attention due to increased environmental concerns and feedstock crisis associated with petroleum-based non-degradable polymers [1,2]. With attractive sustainability, biocompatibility, biodegradability, and mechanical strength, poly(L-lactide) (PLLA) is considered a promising alternative to petroleum-based polymers. However, its wide applications have been obstructed by the inherent brittleness and low heat resistance, as evidenced by the poor impact resistance and tensile toughness as well as low heat distortion temperature (HDT) [3-6]. Therefore, many efforts have been made to improve the toughness and heat resistance of PLLA for expansion of its applications [7-11].

On the one hand, toughening PLLA has gained much interest and various techniques, such as plasticization, chemical copolymerization, and polymer blending, have been employed to toughen PLA [12-15]. Among those, polymer blending with flexible or elastic polymers has proved to be the most cost-effective way to improve the toughness $[6,16]$. It has been noted that directly blending PLLA with most flexible or elastic polymers usually leads to low-performance blends, due to the macro-phase-separated morphology and weak interfacial adhesion arising from the immiscibility between the blending components [17]. Therefore, specific compatibilization is required to fine-tune the morphology and enhance the interfacial adhesion between PLLA and the blending partners $[17,18]$. Dynamic vulcanization, involving selective crosslinking of rubber polymer during melt blending with a thermoplastic polymer, has been demonstrated to be a powerful technique to control the morphology, enhance interfacial adhesion, and improve the final properties of

\footnotetext{
School of Chemistry and Chemical Engineering, Southwest University, Chongqing 400715, China

${ }^{2}$ Key Laboratory of Polymer Processing Engineering, Ministry of Education, South China University of Technology, Guangzhou 510641, China

${ }^{3}$ Center for Degradable and Flame-Retardant Polymeric Materials, College of Chemistry, State Key Laboratory of Polymer Materials Engineering, National Engineering Laboratory of Eco-Friendly Polymeric Materials (Sichuan), Sichuan University, Chengdu 610064, China

* Corresponding author (email: jbzeng@swu.edu.cn)
} 
PLLA blends with elastic polymers [19-23]. Some supertough PLLA blends with impact strengths of more than $530 \mathrm{~J} \mathrm{~m}^{-1}$ (or $53 \mathrm{~kJ} \mathrm{~m}^{-2}$ ) have been achieved by dynamic vulcanization of PLLA with some elastic polymers [22,24-28]. It is worth noting that the sustainability of PLLA was compromised since most elastic polymers in previous studies were prepared from non-renewable feedstocks $[19,25,28,29]$. In this sense, some sustainable elastomers such as natural rubber, epoxidized natural rubber, and bioelastomer have gained much attention in fabricating fully sustainable supertough PLLA via dynamic vulcanization $[22,24,30,31]$.

On the other hand, improving heat resistance has also drawn increasing attention in the area of PLLA modifications [3,32-34]. The poor heat resistance, namely low HDT, arises from the low degree of crystallinity during thermal processing, ascribed to the extremely slow crystallization rate of PLLA. Thus, enhancing the degree of crystallinity $\left(X_{c}\right)$ has been considered one of the most convenient approaches to improve the heat resistance of PLLA [35]. Annealing is useful in increasing the $X_{c}$ of PLLA but requires a very long time to finish crystallization and is thus not favorable for practical processing [36]. Incorporation of nucleating agent provides an efficient way to accelerate the crystallization rate, enhance the $X_{c}$, and improve the heat resistance of PLLA within a short thermal processing time. Many nucleating agents including carbon fillers, cellulose nanocrystals, talc, crystallites of high-melting-point PLLA ( $h$ PLLA), and stereocomplex (SC) crystallites of PLLA and poly(D-lactide) (PDLA) have been employed to enhance the crystallization rate of PLLA [36-42]. Investigations by Yang et al. $[35,37]$ indicated that $h$ PLLA showed the most effective nucleation effect for PLLA when compared to talc and SC crystallites. The melting temperature of $h$ PLLA is very close to that of PLLA; thus, the narrow processing temperature window is unfavorable for practical thermal processing. SC crystallites could be used as the optimal nucleating agent for PLLA, as it has a much higher melting temperature and shows excellent miscibility with PLLA as well as a more effective nucleation effect than that of talc [35,43]. In addition, incorporation of PDLA would change the rheological behavior of PLLA and facilitate morphology regulation of PLLA-based blends $[44,45]$. Therefore, SC crystallites have attracted increasing attention in recent years $[3,4,46]$.

Although the brittleness and low heat resistance are the both major issues for PLLA, it seems that less attention has been paid to resolve both problems simultaneously in recent studies [47-49]. Some investigations have been reported to incorporate the nucleating agent into toughened PLLA blends to enhance heat resistance; however, the elastic polymers used in those studies were usually petroleum-based and thus reduced the sustainability of the resulting materials $[3,48]$. Highly toughened and fully sustainable PLLA materials with excellent heat resistance should be paid more attention from the viewpoint of sustainability [47].

In our previous study, we prepared an unsaturated bioelastomer (UBE) by condensation polymerization of renewable dicarboxylic acids and diols and fabricated a fully sustainable and supertough PLLA blend by dynamical vulcanization with the UBE [30]. In this study, we report a ternary blend consisting of PLLA, PDLA, and vulcanized unsaturated bioelastomer (VUB) by dynamic vulcanization with the aim of enhancing the crystallization rate and heat resistance of the fully sustainable and supertough blend. The effect of PDLA content on the crystallization, morphology, and mechanical properties of the ternary blend has been investigated systematically. We believe that the investigation is of great importance not only for fundamental research but also for sustainable development of the PLLA-based industry.

\section{EXPERIMENTIAL SECTION}

\section{Materials}

Poly(L-lactide) (PLLA) (4032D) with molecular weight $\left(M_{\mathrm{w}}\right)$ of $1.76 \times 10^{5} \mathrm{~g} \mathrm{~mol}^{-1}$ and polydispersity index (PDI) of 2.10 was procured from NatureWorks LLC and used without purification. PDLA with $M_{\mathrm{w}}$ and PDI of $1.85 \times 10^{5}$ $\mathrm{g} \mathrm{mol}^{-1}$ and 1.93 was obtained from Jinan Daigang Biomaterial LLC (China). Itaconic acid (IA) was purchased from Shanghai Macklin Biochemistry Co., Ltd, China. Succinic acid (SA), adipic acid (AA), 1,4-butanediol (BDO), tetraisopropyl titanate (TIPT), hydroquinone monomethyl ether (MEHQ) and dicumyl peroxide (DCP) were all obtained from Kelong Chemical Factory (Chengdu, China). UBE with $M_{\mathrm{w}}$ and PDI of $1.79 \times 10^{5}$ $\mathrm{g} \mathrm{mol}^{-1}$ and 3.24 was prepared from condensation polymerization of SA, AA, IA, and $\mathrm{BDO}$ with mole ratio of 0.35/0.55/0.10/1.05 with 0.05 wt.\% MEHQ and 0.1 wt.\% TIPT as the inhibitor and catalyst, respectively, according to the procedure reported previously [30]. All chemicals were used without purification, and PLLA, PDLA and UBE were vacuum dried at $80^{\circ} \mathrm{C}$ prior to further processing.

Dynamic vulcanization and sample preparation

Dynamic vulcanization was carried out in a Hapro torque 
rheometer (Harbin, China) with two rollers within the mixing chamber at $190^{\circ} \mathrm{C}$ and $80 \mathrm{rpm}$ for $7 \mathrm{~min}$. A series of ternary blends containing $20 \mathrm{wt}$.\% VUB and $80 \mathrm{wt} . \%$ mixture of PLLA/PDLA, in which the content of PDLA varied from 0 to $5,10,15$ and 20 wt.\%, were prepared through dynamic vulcanization. For brevity, the samples were abbreviated to PLLA/VUB/ $x$ PDLA, where $x$ represented the content of PDLA. For example, PLLA/ VUB/10PDLA indicated a sample prepared from $20 \mathrm{wt} \%$ UBE, 72 wt.\% PLLA and 8 wt.\% PDLA, which meant that the content of PDLA was 8 wt.\% for the whole blend and 10 wt.\% for the mixture of PLLA/PDLA. PLLA/VUB was used to indicate the sample without PDLA. The detailed processing procedures are as follow: PLLA, UBE and PDLA with predetermined amounts were first meltblended at $190^{\circ} \mathrm{C}$ for $5 \mathrm{~min}$, then $0.1 \mathrm{wt} . \%$ DCP was added to initiate dynamic vulcanization, which was terminated when the melt torque levelled off ( $\sim 2 \mathrm{~min})$. Neat PLLA in the absence of DCP was also processed with the same procedure for property comparison. Standard notched Izod impact (ISO 179) specimen were injection molded by a Xinshuo MiniJet (Shanghai, China) with barrel and mould temperatures of 200 and $50^{\circ} \mathrm{C}$, respectively. Annealed testing bars were also prepared by injection molding with barrel and mould temperatures of 200 and $120^{\circ} \mathrm{C}$, respectively. The pressure-holding times were 3,22 and $45 \mathrm{~min}$ for PLLA/VUB/PDLA, PLLA/VUB and neat PLLA, respectively. The time was chosen according to isothermal crystallization analysis.

\section{Characterizations}

\section{$X$-ray diffraction (XRD)}

XRD patterns of melt-quenched samples were recorded on an X-ray diffractometer (Philips X'Pert X-ray diffractometer) with $\mathrm{Cu} \mathrm{Ka}$ radiation with a scanning rate of $3^{\circ} / \mathrm{min}$ in the angular region $(2 \theta)$ of $5^{\circ}-40^{\circ}$.

\section{Differential scanning calorimetry (DSC)}

DSC measurement was performed on a NETZSCH DSC214 under nitrogen atmosphere. The heating scans of both the regular injection molded and annealed injection molded samples were recorded to study the thermal transition and crystallization behavior of the samples. About $7 \mathrm{mg}$ sample was used and the measurement was carried out from room temperature to $250^{\circ} \mathrm{C}$ at a heating rate of $10^{\circ} \mathrm{C} \mathrm{min}^{-1}$. For isothermal crystallization investigation, the sample was first melted at $200^{\circ} \mathrm{C}$ for $5 \mathrm{~min}$ to remove any thermal history and then quickly cooled to predetermined temperature and kept until crystallization finished. The exothermic curve was recorded for analysis. Three crystallization temperatures, 110,120 and $130{ }^{\circ} \mathrm{C}$, were chosen for isothermal crystallization investigation.

\section{Polarizing optical microscope (POM)}

The nucleation and spherulitic morphologies were observed on an Olympus BX51 equipment (Olympus Co., Tokyo, Japan) with a Huozi RT600 (Shanghai, China) temperature controller. The hot-pressed films between two microscopic cover glasses were first melted at $200^{\circ} \mathrm{C}$ for $5 \mathrm{~min}$ and then quickly cooled to $120^{\circ} \mathrm{C}$ for isothermal crystallization. Spherulitic morphologies of PLLA matrix were monitored by taking micrographs at an appropriate time interval.

\section{Rheological measurements}

Rheological properties were measured by a DHR-1 (TA, USA) rotational rheometer with a parallel plate geometry (diameter: $25 \mathrm{~mm}$ ), the gap was set at $1 \mathrm{~mm}$. Oscillatory frequency sweeps were performed from 0.01 to $100 \mathrm{~Hz}$ at $190^{\circ} \mathrm{C}$ with a strain of $1 \%$.

\section{Impact strength}

The notched Izod impact strength of regular and annealed injection molded samples was measured on a Sansi ZBC7000 (Shenzhen, China) impact tester at room temperature in general accordance with ASTM D256. Five measurements were carried out for each sample and the averaged result was reported.

\section{Morphological analysis}

The phase morphologies for the cryo-fractured surfaces of the samples were observed using scanning electron microscopy (SEM, XL-30s FEG, Philips, Holland) at an accelerating voltage of $5 \mathrm{kV}$. The surfaces were coated with a layer of gold in a vacuum chamber before observation. The morphology for the impact-fractured surfaces of the samples were observed on a JSM-6510 equipment (JEOL, Japan) at an accelerating voltage of $20 \mathrm{kV}$. The surfaces were also coated with a layer of gold before observation.

\section{Heat resistance}

Thermo-mechanical properties were measured on a Q800 dynamic mechanical analyzer (TA Instruments) under a tensile mode at oscillation frequency of $1 \mathrm{~Hz}$ from 0 to $150^{\circ} \mathrm{C}$ at a heating rate of $3^{\circ} \mathrm{C}$ min. The samples with $0.7 \mathrm{~mm}$ thickness were prepared by compression molding at $190^{\circ} \mathrm{C}$ under a pressure of $10 \mathrm{MPa}$. Two series of samples, i.e., quenched and annealed, were prepared for 
property comparison. The quenched sample were prepared by directly immersing the melted compression molded sample into ice-water mixture. Annealed PLLA/ VUB sample was prepared by placing the melted compression molded sample in to a $120^{\circ} \mathrm{C}$ oven for $22 \mathrm{~min}$ and the annealed PLLA/VUB/PDLA samples were prepared by placing the melted compression molded samples in to a $120^{\circ} \mathrm{C}$ oven for $3 \mathrm{~min}$. The heat resistance of the samples was further directly observed by placing the compression molded sample with a $50 \mathrm{~g}$ weight hung in the middle into an $80^{\circ} \mathrm{C}$ oven for $5 \mathrm{~min}$ to observe the dimension stability of the samples.

\section{RESULTS AND DISCUSSION}

\section{Dynamic vulcanization}

Dynamic vulcanization is usually monitored by the variation of melt torque versus time during operation in rheometer. Fig. 1 shows the evolution of torque with time for all the samples. The obvious change in initial stage corresponds to the addition of solid materials and their melt. After melting completely, the melt torques of neat PLLA and PLLA/VUB decrease slightly which may be attributed to the shear thinning and possible thermal degradation of the aliphatic polyesters during melting processing $[50,51]$. It is interesting to find that the PLLA/ VUB/PDLA ternary blends show higher melt torque after melting compared to the PLLA/VUB binary blends, and the torque value increases with increase in the PDLA content. In addition, there is an increase in melt torque after complete melt and the increment goes up with increase in the PDLA content. The phenomenon is attributed to the formation of SC crystallites, which possess high modulus and act as solid fillers to reinforce the blends and increase the elastic response of the melt [44]. It is obvious that the melt torques of both PLLA/VUB binary and PLLA/VUB/PDLA ternary blends increase drastically after addition of DCP, which corresponds to the formation of VUB crosslinking structure by dynamic vulcanization. After reaching the max value, the melt torque almost level off at $\sim 2$ min after addition of DCP, indicating the end of dynamic vulcanization. The final melt torque of the blends first increases with increasing PDLA content and then remains unchanged when the content of PDLA increases to more than $10 \mathrm{wt} \%$, indicating that the influence of SC crystallites on the melt behavior of dynamically vulcanized blends becomes less prominent when the content of PDLA increases to more than $10 \mathrm{wt} . \%$, due to the formation of VUB crosslinking structures which dominate the melt behavior of the final

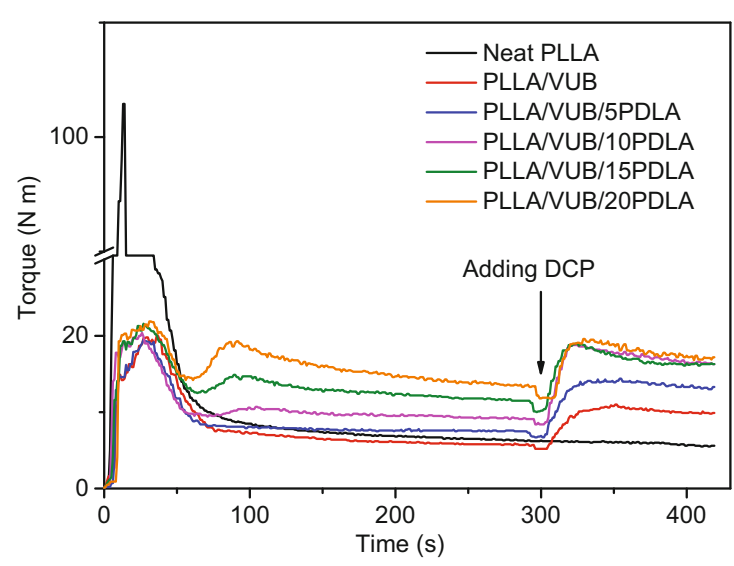

Figure 1 Melt torque versus reactive blending time for neat PLLA and PLLA/VUB/PDLA blends.

blends.

\section{Rheological behavior}

Rheology is a powerful technique to study the microstructure of polymer blends from the variation of melt viscosity and storage modulus [52]. The rheological behavior of neat PLLA, PLLA/VUB binary and PLLA/VUB/ PDLA ternary blends was studied by rotational rheometer at $190^{\circ} \mathrm{C}$ under frequency-sweep mode from 0.01 to $100 \mathrm{~Hz}$. Fig. 2 shows the frequency dependences of complex viscosity $\left(\left|\eta^{*}\right|\right)$ and storage modulus $\left(G^{\prime}\right)$ for the samples. Neat PLLA showes a typical liquid-like response at low frequency range due to the terminal behavior as evidenced by the absence of plateau, as shown in the $G^{\prime}-f$ plots in Fig. 2a. While all blends show solid-like response due to the presence of nonterminal plateau at low frequency, indicating the formation of VUB network structures in the polylactide matrix by dynamic vulcanization, which restrict the chain mobility of the matrix to exhibit slower relaxation. Incorporation of PDLA strengthens the solid-like response, due to the formation of SC crystallites, which reduces the chain mobility of the matrix through forming SC network structure to further retard the relaxation. With increase in the content of PDLA, higher concentrated SC crystallites form, bringing about more significant chain mobility restriction. Therefore, the ternary blends show more prominent solid-like response at higher PDLA content, as evidenced by the higher storage modulus.

Complex viscosity of neat PLLA almost remains unchanged at low frequency and decreased apparently at high frequency as shown in Fig. $2 b$, which indicates a transition from the Newtonian plateau to power law regime at the inflection point. Newtonian plateau dis- 

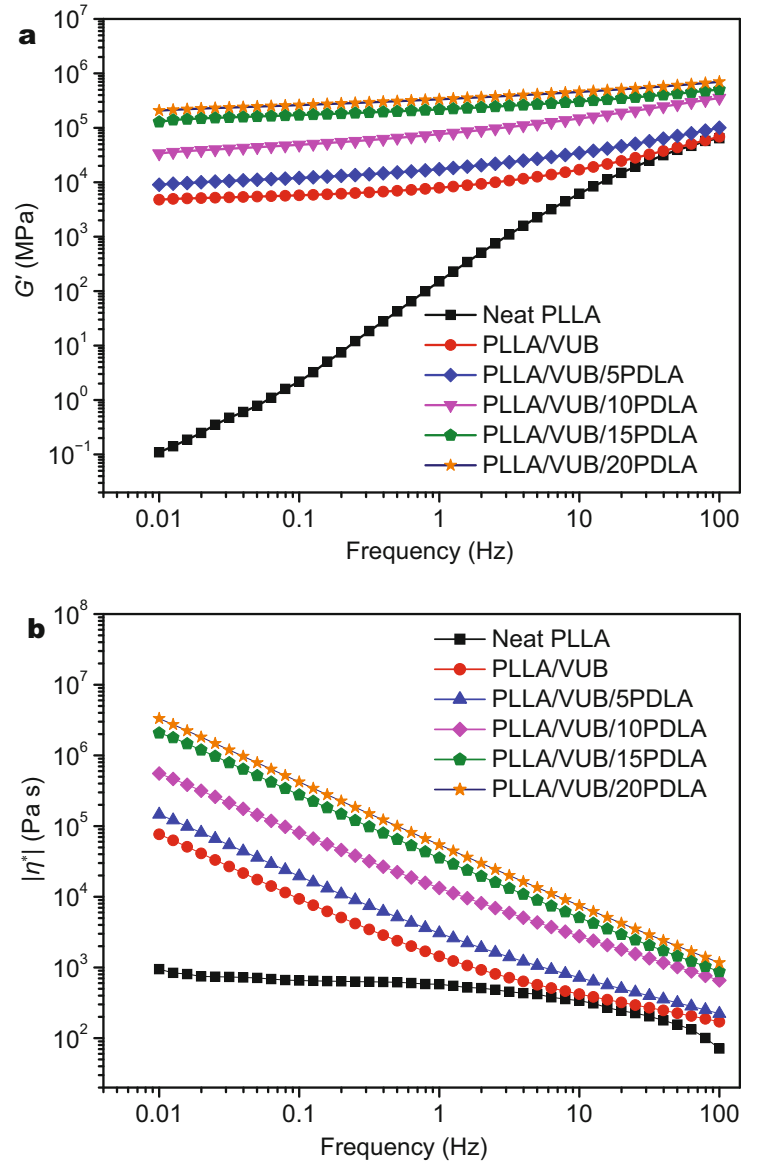

Figure 2 Variation of storage modulus $\left(G^{\prime}\right)$ (a) and complex viscosity $\left(\eta^{*}\right)$ (b) as a function of frequency for neat PLLA and PLLA/VUB blends with different contents of PDLA. The measurements were performed with a strain of $1 \%$ at $190^{\circ} \mathrm{C}$

appears for all blends in the low frequency range due to the formation of VUB network structures, which enhance the non-Newton behavior of the samples. Instead, shearshinning occurs in the full frequency range for all the blends. Besides the crosslinking structure of VUB, the interfacial interaction between VUB and polylactide matrix would also restrict the chain mobility of the matrix molecular chains. Increasing PDLA content increases the complex viscosity at given frequency and enhances the shear-shinning behavior, which is also ascribed to the formation of more concentrated SC crystallites to reduce the chain mobility of the matrix. The above discussion indicates that crosslinking of VUB occurs and SC crystallites form successfully during dynamic vulcanization [53].

\section{SC crystallite analysis}

In order to get direct evidence for the formation of SC

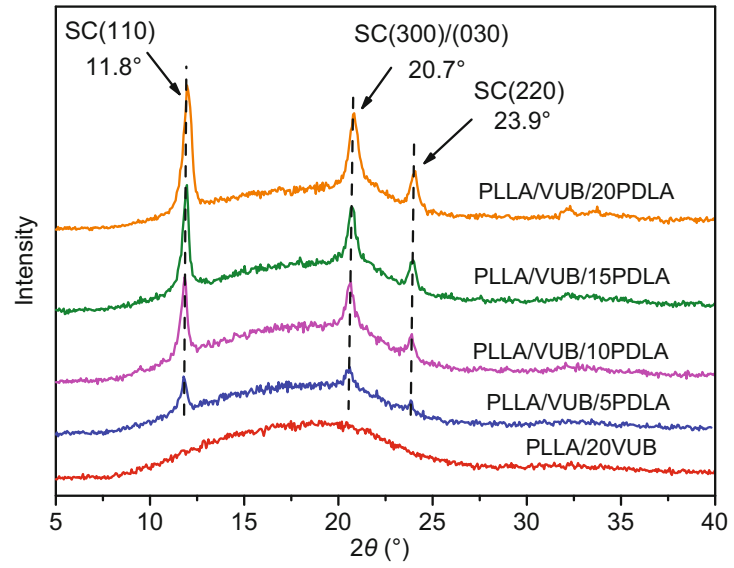

Figure 3 XRD patterns of melt-quenched PLLA/VUB binary and PLLA/VUB/PDLA ternary blends.

crystallites, XRD patterns of melt-quenched PLLA/VUB binary and PLLA/VUB/PDLA ternary blends were recorded as show in Fig. 3. The PLLA/VUB binary blends show amorphous feature without characteristic sharp peak, while PLLA/VUB/PDLA ternary blends show three distinct characteristic peaks at $2 \theta$ values of $11.8^{\circ}, 20.7^{\circ}$ and $23.9^{\circ}$, corresponding to the (110), (300)/(030), and (220) planes of SC crystallites, respectively [54]. In addition, the peak intensity increases with PDLA content, which is attributed to the increase in the content of SC crystallites. The results indicate that SC crystallites are successfully formed during the melt processing.

\section{Isothermal crystallization}

Isothermal crystallization was studied to evaluate the effect of PDLA on the crystallization of the blends. Fig. 4 shows the exothermic curves of neat PLLA, PLLA/VUB binary and PLLA/VUB/PDLA ternary blends during isothermal crystallization at 110,120 and $130^{\circ} \mathrm{C}$. For all the samples, the time required to complete crystallization increases with increasing temperature. Neat PLLA shows the smallest crystallization rate at all temperatures. For example, the time to finish crystallization at $120^{\circ} \mathrm{C}$ is about $45 \mathrm{~min}$ for neat PLLA. The time required to complete crystallization decreases by almost a half at the same temperature for PLLA/VUB binary blends compared to neat PLLA, indicating an accelerated crystallization rate, which could be ascribed to the increased nucleating density arising from the interfacial nucleation of phase-separated PLLA/VUB blends [55]. The time for all PLLA/VUB/PDLA ternary blends to finish crystallization reduces significantly, compared to both neat PLLA and PLLA/VUB binary blends, due to the increased 

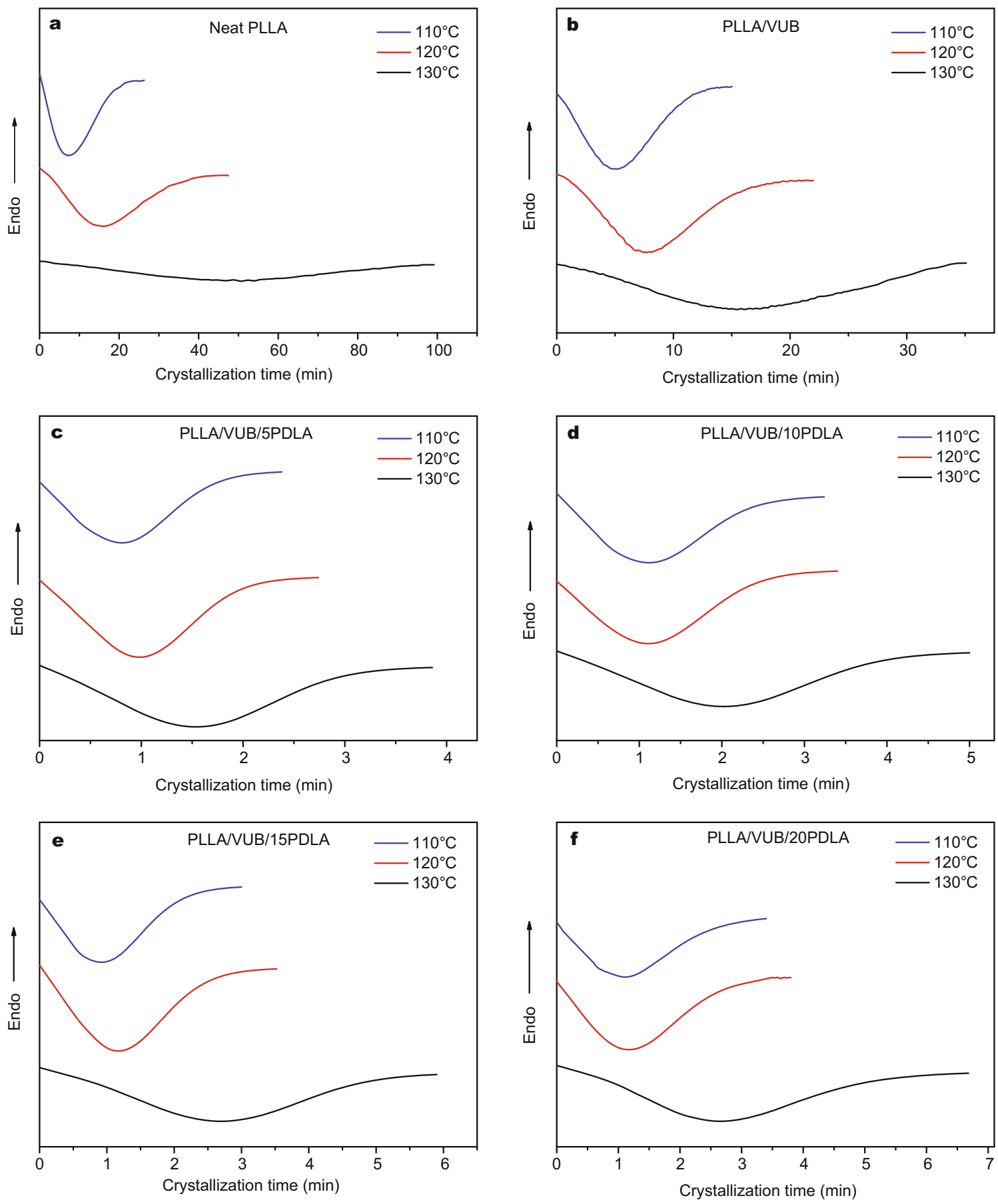

Figure 4 DSC exothermic curves for isothermal crystallization of the samples.

nucleation efficiency by the presence of SC crystallites. It is noted that the content of PDLA hardly affects the crystallization rate of the blends, since the time for full crystallization almost does not change with PDLA content, which indicates that $5 \mathrm{wt} \%$ PDLA is sufficient to drastically accelerate the crystallization rate of PLLA. All the ternary blends finish crystallization at $3 \mathrm{~min}$ at $120^{\circ} \mathrm{C}$, which is only $\sim 1 / 7$ as that of PLLA/VUB binary and $\sim 1$ / 14 as that of neat PLLA.

Spherulitic growth and morphology

POM measurement was performed to show the effect of 

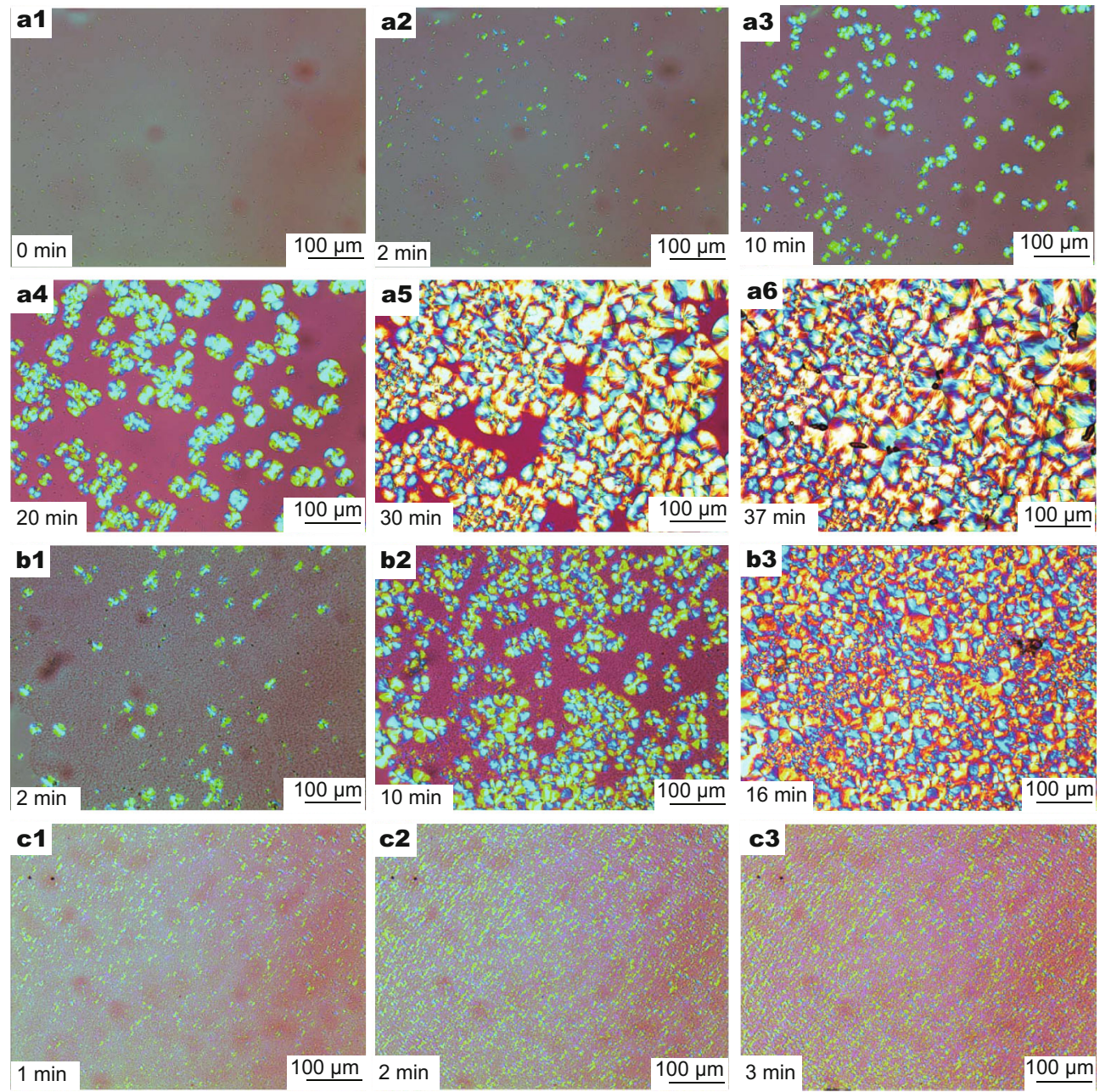

Figure 5 POM micrographs showing evolution of spherulitic morphology with time for neat PLLA (a), PLLA/VUB binary (b) and PLLA/VUB/ 10PDLA ternary blends (c).

blending and formation of SC crystallites on nucleation behavior and spherulitic growth of PLLA matrix. Fig. 5 shows the evolution of spherulitic morphology with time for neat PLLA, PLLA/VUB binary blend and PLLA/VUB/ 10PDLA ternary blend during isothermal crystallization at $120^{\circ} \mathrm{C}$. Neat PLLA shows the lowest nucleating density, the largest spherulites and the longest period to finish crystallization, corresponding to its slow crystallization rate. PLLA/VUB binary blends show smaller spherulites and increased nucleating density, compared to neat PLLA, which enhances the crystallization rate of the PLLA matrix with the time to finish crystallization shortened to $16 \mathrm{~min}$. The increased nucleating density is attributed to promoted heterogeneous nucleation from the phase-separated interface of PLLA/VUB blend. For PLLA/VUB/PDLA ternary blends, regular spherulites are hard to distinguish, due to the highly concentrated nu- cleating density resulting from the presence of SC crystallites. The morphology keeps unchanged after isothermal crystallization for $3 \mathrm{~min}$, indicating completed crystallization.

\section{Degree of crystallinity}

Two series of injection molded samples were prepared by regular injection and annealed injection. For the regular injection, the barrel and mould temperatures were 200 and $50^{\circ} \mathrm{C}$, respectively, and the pressure-holding times were $10 \mathrm{~s}$ for all samples. In the case of annealed injection, the barrel and mould temperatures were 200 and $120^{\circ} \mathrm{C}$, respectively, and the pressure-holding times were 45, 22 and 3 min for neat PLLA, PLLA/VUB binary and PLLA/VUB/PDLA ternary blends, respectively. The DSC heating scans of the both series of injection molded samples were recorded to study the crystallization beha- 

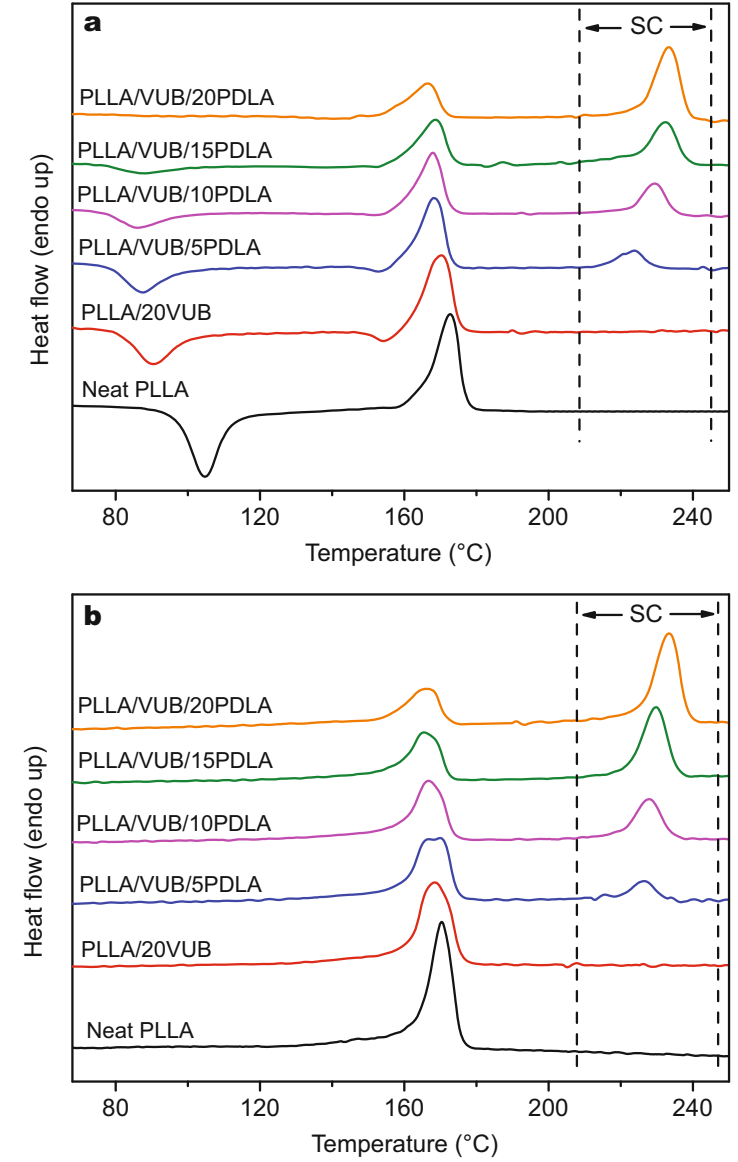

Figure 6 DSC heating scans for regular injection molded (a) and annealed injection molded $120^{\circ} \mathrm{C}(\mathrm{b})$ samples.

vior and thermal transition of the samples, as shown in Fig. 6. From the heating scans of regular injection molded samples (Fig. 6a), we can see that neat PLLA shows obvious cold crystallization peak at $\sim 105^{\circ} \mathrm{C}$, indicating that it hardly crystallizes during regular injection molding. PLLA/VUB binary blends also show obvious cold crystallization peak at $90.5^{\circ} \mathrm{C}$, which is much lower than that of neat PLLA, due to the increased nucleation efficiency arising from interfacial nucleation of phase-separated PLLA/VUB blends. PLLA/VUB/PDLA ternary blends show weaker cold crystallization compared to both neat PLLA and PLLA/VUB binary blends. The crystallization peak becomes less prominent and shifts to lower temperature range with increase in the content of PDLA. When PDLA content increases to $20 \mathrm{wt} . \%$, the cold crystallization disappears. The phenomenon indicates that PLLA matrix in the ternary blends crystallizes during regular injection molding, and achieves higher degree of crystallinity $\left(X_{c}\right)$ with increasing PDLA content. When the content of PDLA increases to $20 \mathrm{wt} \%$, the PLLA matrix finishes crystallization during the regular processing, due to the highest nucleation efficiency by the presence of most concentrated SC crystallites.

Both neat PLLA and PLLA/VUB binary blends show a single melting peak at $\sim 170^{\circ} \mathrm{C}$, while all the ternary blends show double melting peaks with one at about $170^{\circ} \mathrm{C}$ and the other at around $235^{\circ} \mathrm{C}$, corresponding to the melt of PLLA matrix and SC crystallites, respectively, which also confirms the formation of SC crystallites during melt processing. It is interesting to find that the melting temperature of PLLA in the blends decreases slightly with increase in the content of PDLA, which may be attributed to the reduced size and regularity of the crystals of PLLA by increasing nucleation density.

The matrix crystallinity $\left(X_{\mathrm{m}}\right)$, by assuming that PLLA and PDLA form SC crystallites with weight ratio of 1:1 [44], can be calculated by the following equations:

$$
\begin{gathered}
X_{\mathrm{m}}=f_{\mathrm{hc}} X_{\mathrm{hc}}+f_{\mathrm{sc}} X_{\mathrm{sc}} \\
X_{\mathrm{hc}}=\frac{\Delta H_{\mathrm{m}, \mathrm{hc}}-\Delta H_{\mathrm{cc}}}{\left(w_{\mathrm{L}}-w_{\mathrm{D}}\right) \Delta H_{\mathrm{m}, \mathrm{hc}}^{\mathrm{o}}} \times 100 \% \\
X_{\mathrm{sc}}=\frac{\Delta H_{\mathrm{m}, \mathrm{sc}}}{2 w_{\mathrm{D}} \Delta H_{\mathrm{m}, \mathrm{sc}}^{\mathrm{o}}} \times 100 \%
\end{gathered}
$$

where $f_{\mathrm{hc}}$ is the weight fraction of PLLA residue that does not cocrystallize with PDLA and $f_{\mathrm{sc}}$ is the weight fraction of PDLA plus the equal amount of PLLA, $X_{\mathrm{hc}}$ and $X_{\mathrm{sc}}$ are the crystallinity of homo-PLLA and SC-PLLA/PDLA, Where $\Delta H_{\mathrm{m}, \mathrm{hc}}$ is fusion enthalpy of PLLA at $\sim 170^{\circ} \mathrm{C}$, $\Delta H_{\mathrm{m}, \mathrm{sc}}$ is the fusion enthalpy of SC crystals at $\sim 235^{\circ} \mathrm{C}$, $\Delta H_{\mathrm{cc}}$ is the cold crystallization enthalpy, $w_{\mathrm{L}}$ and $w_{\mathrm{D}}$ are the weight fractions of PLLA matrix and PDLA of the ternary blends, respectively, and $\Delta H_{\mathrm{m}, \mathrm{hc}}^{\mathrm{o}}, \Delta H_{\mathrm{m}, \mathrm{sc}}^{\mathrm{o}}$ are the melting enthalpy of completely crystalline homo-PLLA and SC, being 93.6 and $142 \mathrm{~J} \mathrm{~g}^{-1}$, respectively [56]. The $X_{\mathrm{m}}$ of neat PLLA is only $5.5 \%$, and that in PLLA/VUB binary blends is $15.8 \%$. The $X_{\mathrm{m}}$ of the PLLA/VUB/PDLA ternary blends increases gradually to $18.7,28.3,36.7$ and $42.8 \%$ with the content of PDLA increases to 5, 10, 15 and 20 wt.\%, respectively.

Cold crystallization disappears in the heating scans of all annealed injection molded samples, as shown in Fig. $6 \mathrm{~b}$, indicating that all samples finish crystallization during injection annealing. The $X_{\mathrm{m}}$ of neat PLLA is $46.4 \%$, while those of the blends increase to $46.3,46.7,46.3,45.7$ and $45.8 \%$ for the matrix of PLLA/VUB, PLLA/VUB/5PDLA, PLLA/VUB/10PDLA, PLLA/VUB/15PDLA, and PLLA/ VUB/20PDLA, respectively. Furthermore, it should be noted that the annealing time was different for neat 
PLLA, PLLA/VUB binary blends and PLLA/VUB/PDLA ternary blends. The ternary blends show much higher processing efficiency since the annealing time was only $3 \mathrm{~min}$, whereas the annealing times were 22 and $45 \mathrm{~min}$ for PLLA/VUB binary and neat PLLA, respectively. Therefore, it is concluded that incorporation of PDLA not only accelerates the crystallization rate but also enhances the degree of crystallinity of the matrix of the blends.

\section{Phase morphology}

SEM experiment was performed for PLLA/VUB binary and PLLA/VUB/PDLA ternary blends to study the effect of PDLA on the phase morphology of the samples. Fig. 7 shows the SEM micrographs of cryo-fractured surfaces of both regular and annealed injection molded samples. Although phase-separated morphology is observed for all the samples, no obvious gaps between dispersed VUB and polylactide matrix could be observed, indicating strong interfacial adhesion between VUB and the matrix due to the interfacial compatibilization [30]. It is hard to discriminate VUB phase from the matrix for regular injection molded PLLA/VUB binary (Fig. 7a) and PLLA/VUB/ PDLA ternary blends with PDLA content of no more than 10 wt.\% (Fig. $7 \mathrm{~b}$ and c). With further increase in the content of PDLA, dispersed VUB phase (as included in red circle) becomes observable and the size of dispersed VUB phase seems to increase with increasing PDLA content, indicating an enhanced extent of phase-separation, which should be ascribed to the significantly enhanced viscosity of the matrix phase by incorporation of PDLA, which forms SC crystallites with PLLA to reduce the chain mobility of the matrix. We can reasonably assume that the final melt viscosity of cross-linked VUB phase after dynamic vulcanization did not change with the content of PDLA, since the crosslinking density of VUB did not change, while the melt viscosity of the matrix increased significantly, which would restrict the mutual diffusion between two phases. Therefore, the dispersed phase becomes easily distinguishable and the phase size increases gradually with increase in the content of PDLA.

The morphology of annealed injection molded samples show the similar variation tendency with increase in the content of PDLA. After careful observation, we can find that although the boundaries between dispersed VUB and the matrix are still undistinguishable on the surface of annealed PLLA/VUB (Fig. 7a') and PLLA/VUB/5PDLA (Fig. $7 \mathrm{~b}^{\prime}$ ), the dispersed VUB particles become observable on the surface of annealed injection molded PLLA/VUB/ 10PDLA (Fig. $7 \mathrm{c}^{\prime}$ ). Compared to regular injection molded
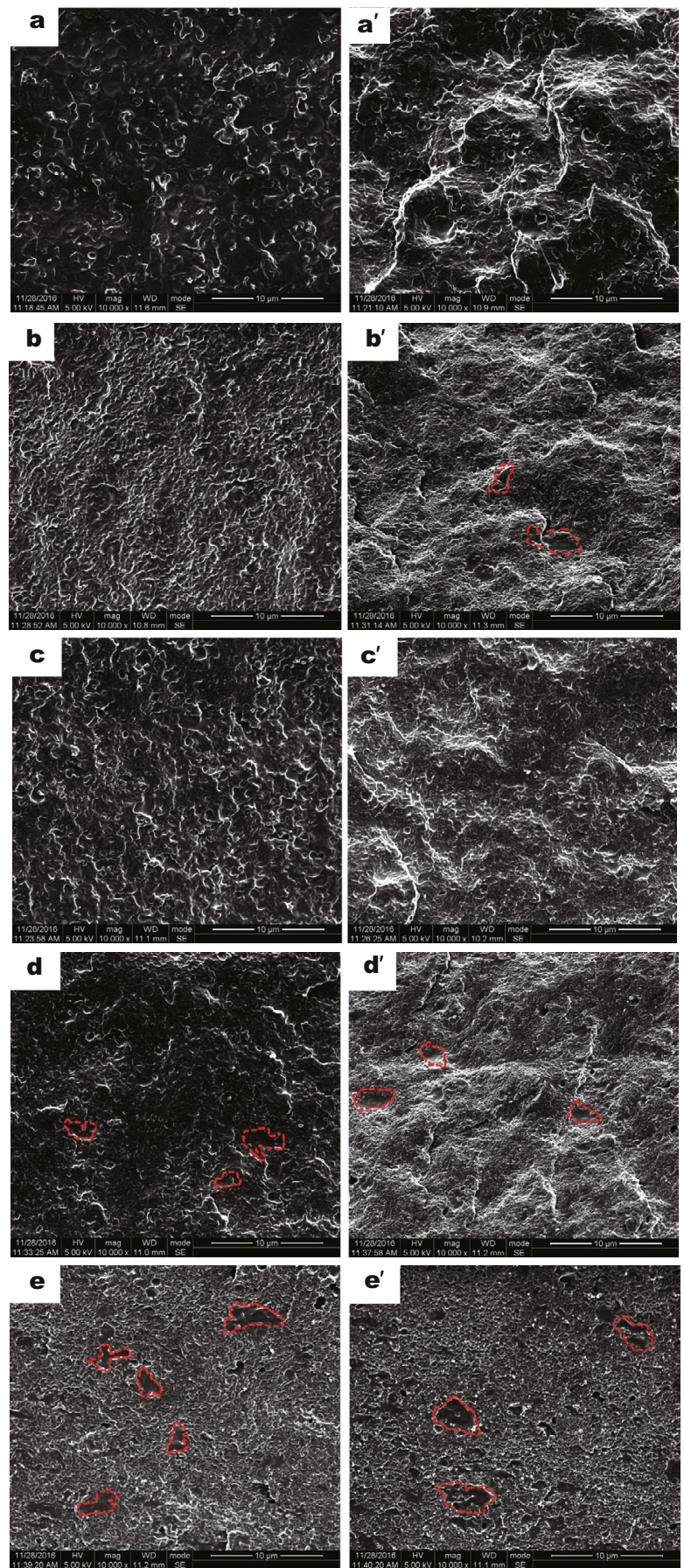

Figure 7 SEM micrographs of cryo-fractured surfaces of the blends with injection molded: (a) PLLA/VUB, (b) PLLA/VUB/5PDLA, (c) PLLA/VUB/10PDLA, (d) PLLA/VUB/15PDLA and (e) PLLA/VUB/ 20PDLA and $\left(\mathrm{a}^{\prime}-\mathrm{e}^{\prime}\right)$ their corresponding annealed specimens.

counterpart, on the surface of which the dispersed VUB particles are hard to observe (Fig. $7 \mathrm{c}$ ), we could conclude that phase separation enhanced by annealing, possibly due to that the surrounded dispersed phase and small 
particles would be excluded from the crystals of the matrix during annealing crystallization process to form larger aggregated phase. Due to the crosslinking structure of VUB phase, it could not undergo excessive deformation during the annealing process. Therefore, the increment in particle size by annealing seems very limited, which could be clearly demonstrated by comparing Fig. $7 \mathrm{e}$ and $\mathrm{e}^{\prime}$. Although some large dispersed particles on the surface of annealed PLLA/VUB/20PDLA are greater than those of regular PLLA/VUB/20PDLA, a large amount of small dispersed particles on both surfaces have similar structure and sizes.

\section{Notched Izod impact strength}

The notched Izod impact strengths of the two series of samples were comparatively studied and the results are graphically shown in Fig. 8. The regular injection molded brittle neat PLLA shows an Izod impact strength of $32.2 \mathrm{~J} \mathrm{~m}^{-1}$. After dynamic vulcanization, super-tough PLLA/VUB binary blend is achieved with the impact strength increased to more than $575.9 \mathrm{~J} \mathrm{~m}^{-1}$. It is interesting to find that the impact strength of PLLA/VUB binary blends could increase obviously with incorporation of PDLA. The values increase to 619.5 and $659.9 \mathrm{~J} \mathrm{~m}^{-1}$ with 5 and $10 \mathrm{wt} . \%$ PDLA, respectively. While the impact strength decreases gradually to 610.8 and $498.3 \mathrm{~J} \mathrm{~m}^{-1}$, with further increasing the PDLA content to 15 and 20 wt.\%. Several factors including phase morphology, molecular entanglement and matrix crystallinity affect the impact strength of the PLLA/VUB/PDLA ternary blends. The discussion in the section of "phase morphology" indicates that although the dispersed VUB particle size increases slightly with the content of PDLA, the change in size of VUB particle is clearly detectable only when the content of PDLA is more than $15 \mathrm{wt} . \%$ especially at $20 \mathrm{wt} . \%$. When the content of PDLA is $\leq 10$ wt.\%, the phase morphology keeps almost unchanged. The increase in the size of VUB particles could result in reduced impact strength, as the size of some particles is greater than $3 \mu \mathrm{m}$ for PLLA/VUB/20PDLA as shown in Fig. $7 \mathrm{e}$, which is much larger than the optimum size $(\sim 0.75 \mu \mathrm{m})$ for highly toughened amorphous or low crystalline PLLA matrix [57]. The enhancement in molecular entanglement of the matrix by incorporation of PDLA is helpful for improving impact strength of PLLA [48], while higher crystallinity of the matrix is harmful, because it would make the matrix shear yielding more difficult [58]. The combination of the variations of phase morphology, molecular entanglement and matrix crystallinity accounts for the variation tendency of the blends

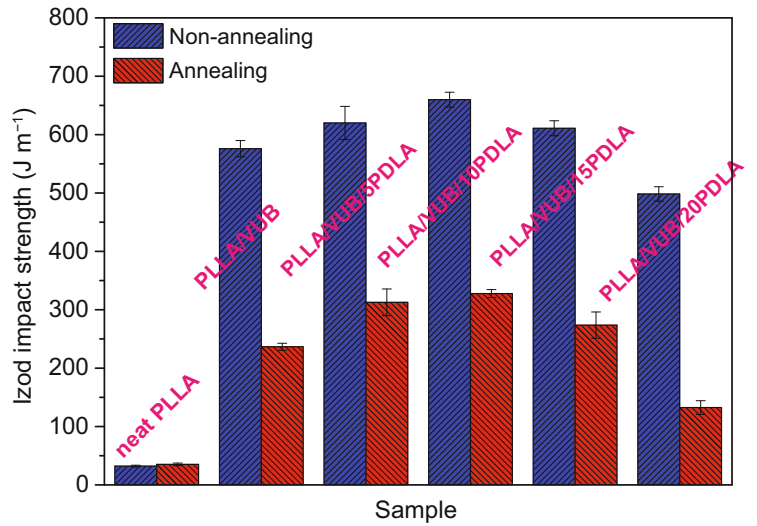

Figure 8 Notched Izod impact strength of different samples.

versus PDLA content. For the blends with PDLA content $\leq 10 \mathrm{wt} . \%$, both the phase morphology and matrix crystallinity change slightly, while the molecular entanglement increases significantly, corresponding to the obviously enhanced impact strength. With PDLA content further increases, the positive effect of increasing molecular entanglement is counterbalanced or even overwhelmed by the negative effects of increasing VUB particle size combined with enhancing matrix crystallinity, resulting in reduced impact strength.

The annealed injection molded neat PLLA shows an impact strength of $35.2 \mathrm{~J} \mathrm{~m}^{-1}$, very close to that of regular molded counterpart. The impact strength of annealed PLLA/VUB binary blend is $236.6 \mathrm{~J} \mathrm{~m}^{-1}$, which is $\sim 6.7$ times higher than that of neat PLLA, indicating VUB is still efficient in toughening highly crystalline PLLA matrix. The change in impact strength with the content of PDLA for PLLA/VUB/PDLA ternary blends is similar to that observed in regular molded samples. For this series, the effect of matrix crystallinity on the impact toughness could be reasonably neglected due to the close $X_{\mathrm{c}}$ values of all samples. Thus the molecular entanglement and phase morphology control the change of impact strength of the ternary blends with different PDLA contents. Molecular entanglement dominates the change of impact strength with the PDLA content of $\leq 10$ wt.\%, whereas, phase morphology dominates if the PDLA content is $\geq 15$ wt.\%. Therefore, the impact strength of the ternary blends first increases to 312.8 and $327.8 \mathrm{~J} \mathrm{~m}^{-1}$ with addition of 5 and 10 wt.\% PDLA and then decreases to 273.7 and $132.5 \mathrm{~J} \mathrm{~m}^{-1}$ with PDLA content further increases to 15 and $20 \mathrm{wt. \%}$, respectively. The impact strength of annealed injection molded ternary blends is much smaller than that of regular injection molded counterparts, but the values are several times higher than that of so-called 

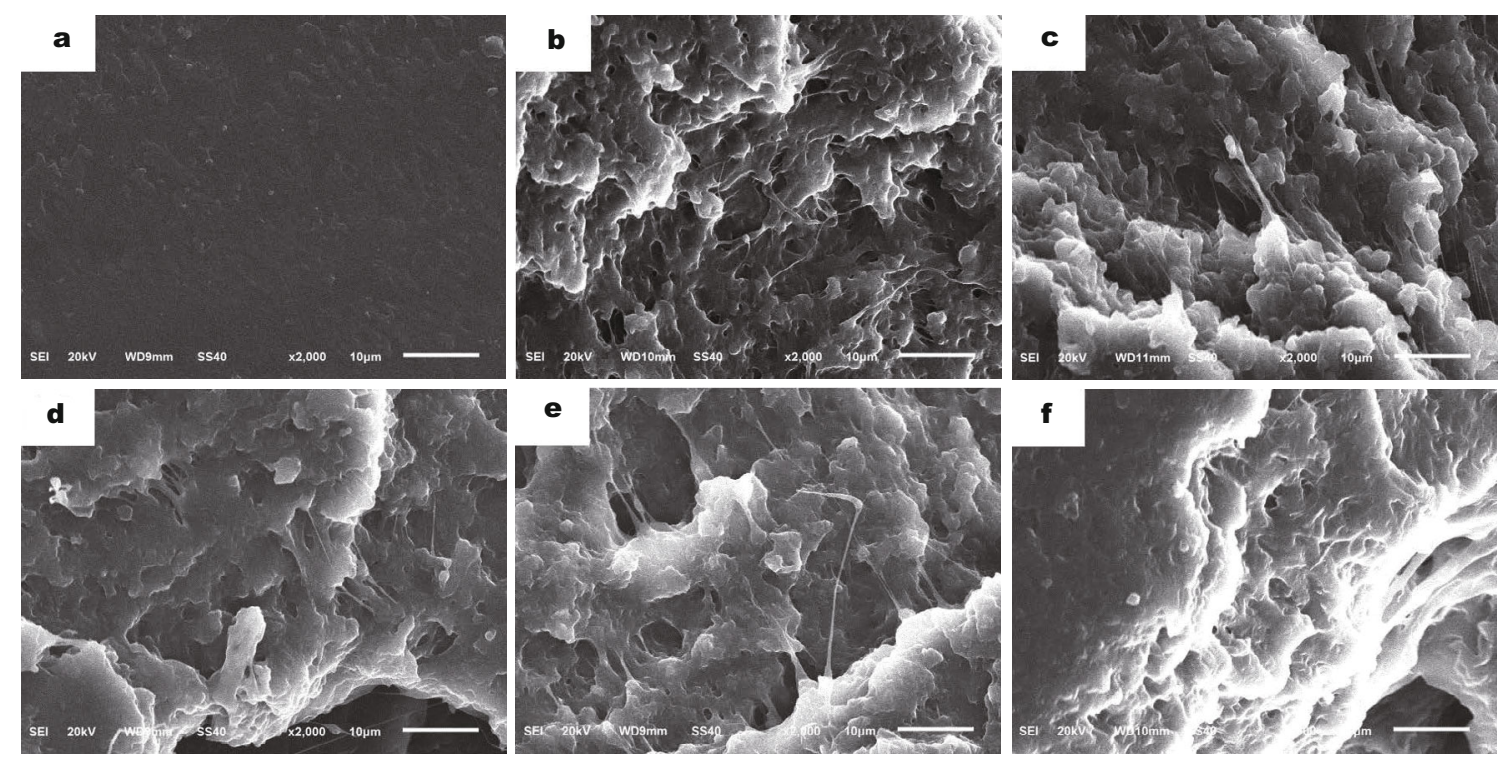

Figure 9 SEM images for the impact-fractured surfaces of regular injection molded samples: neat PLLA (a), PLLA/VUB (b), PLLA/VUB/5PDLA (c), PLLA/VUB/10PDLA (d), PLLA/VUB/15PDLA (e) and PLLA/VUB/20PDLA (f).

high-impact polystyrene with the notched Izod impact strength of $72.5 \mathrm{~J} \mathrm{~m}^{-1}$ [59]. Therefore, the annealed injection molded fully bio-based ternary blends may have the potential to replace non-sustainable HIPS in many applications from the viewpoint of toughness.

The impact-fractured surfaces of the two series of samples were observed by SEM to show some insights into the impact toughness of the samples. Fig. 9 shows the SEM micrographs of regular injection molded samples. Neat PLLA shows typical brittle fracture behavior with a smooth surface. PLLA/VUB binary and all PLLA/VUB/ PDLA ternary blends show similar particularly rough fractured surfaces, where massive matrix plastic deformation, as evidenced by the matrix shear yielding and fibrillation, could be clearly found. Formation of this kind of surfaces upon impact loading could dissipate considerable impact energy to exhibit super-toughened impact toughness.

Fig. 10 shows the SEM micrographs of the annealed injection molded samples. It is noted that annealed PLLA shows somewhat coarser surface than the regular counterpart, corresponding to slightly increased impact strength of the former compared to the latter. For the annealed PLLA/VUB binary and PLLA/VUB/PDLA ternary blends, the matrix shear yielding and fibrillation are almost unobservable possibly due to the reduced deformability of the highly crystalline matrix achieved upon annealing. However, microvoids induced matrix plastic deformation could be observed, which could also lead to large impact energy dissipation, accounting for the highly improved impact strength of the annealed binary and ternary blends compared to neat PLLA.

\section{Heat resistance}

The heat resistance of representative melt-quenched samples was measured by DMA and compared with that of annealed counterparts. Fig. 11a shows the plots of storage modulus $\left(E^{\prime}\right)$ versus temperature for the samples. There is an obvious drop in $E^{\prime}$ in the range of $58-82^{\circ} \mathrm{C}$ for all the samples, corresponding to the $\alpha$-relaxation, i.e., glass transition, of the matrix. The amorphous binary and ternary blends show considerable drop during the a-relaxation with the minimum storage modulus decreased to 0.9, 2.5 and 5.1 MPa for PLLA/VUB, PLLA/VUB/5PDLA and PLLA/VUB/10PDLA, respectively, indicating poor heat resistance. After reaching the minimum value, the storage modulus increases with higher values, attributing to the crystallization of the polylactide matrix. For the annealed samples, the loss in $E^{\prime}$ is much smaller than that of melt-quenched counterparts, indicating enhanced heat resistance, which is ascribed to the reinforced stiffness of the sample as a result of highly crystallinity. No rise in $E^{\prime}$ is observed after glass transition, which indicates that all the annealed samples finished crystallization during annealing even with only $3 \mathrm{~min}$ for the two ternary blends. However, it should be noted that the annealing time was $22 \mathrm{~min}$ for PLLA/VUB binary blends, which was much longer than that of the ternary blends, indicating a low 

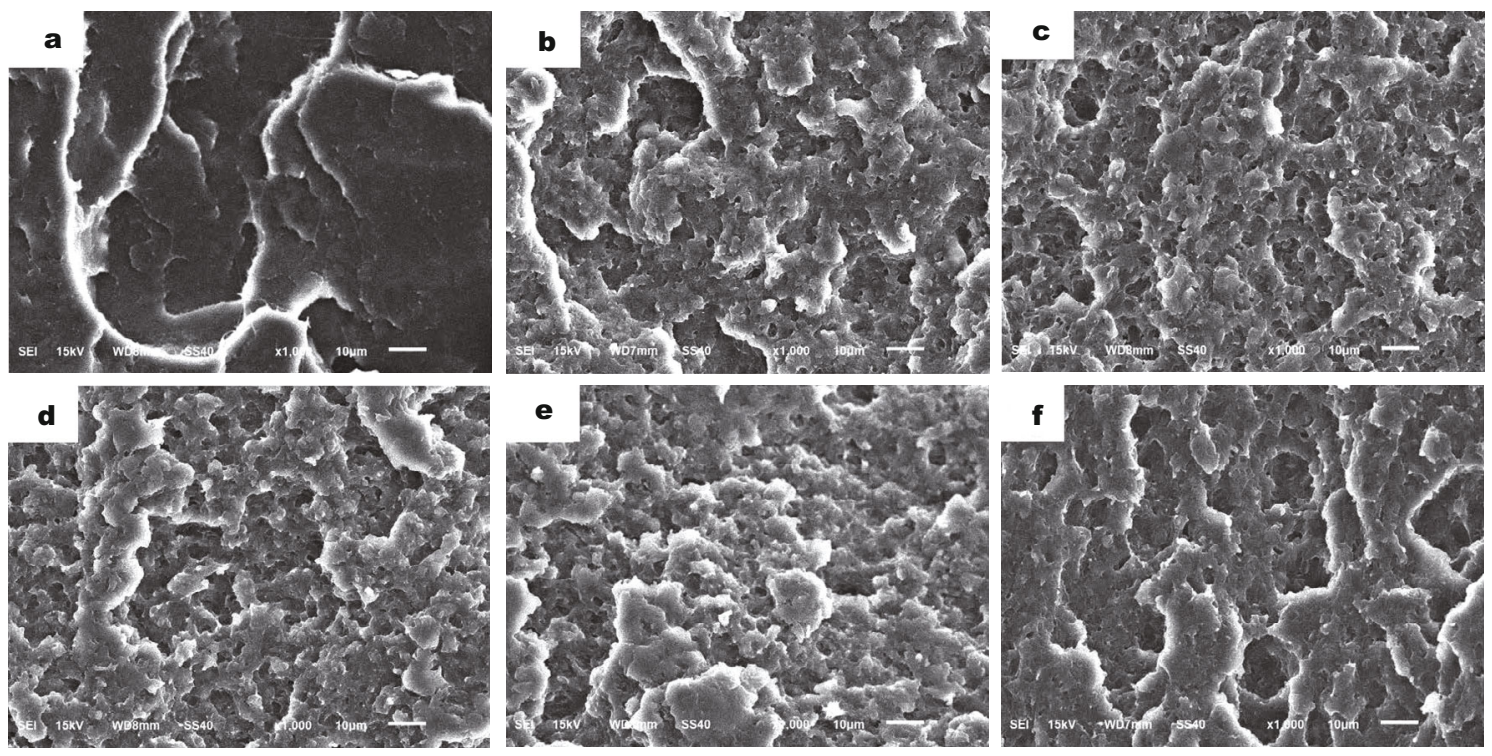

Figure 10 SEM images for the impact-fractured surfaces of annealed injection molded samples: neat PLLA (a), PLLA/VUB (b), PLLA/VUB/5PDLA (c), PLLA/VUB/10PDLA (d), PLLA/VUB/15PDLA (e) and PLLA/VUB/20PDLA (f).

processing efficiency for the binary blends. Furthermore, it is worth noting that the PLLA/VUB/PDLA ternary blends show higher $E^{\prime}$ values than PLLA/VUB binary blend at a given temperature such as $80^{\circ} \mathrm{C}$. The $E^{\prime}$ value is 166.3 $\mathrm{MPa}$ for PLLA/VUB, which increases to 275.0 and 283.3 $\mathrm{MPa}$ for PLLA/VUB/5PDLA and PLLA/VUB/ 10PDLA, respectively, which demonstrates that the formation of SC crystallites in the polylactide matrix could enhance the heat resistance of the toughened blends. The annealed samples hold high $E^{\prime}$ values even with temperature increased to $140^{\circ} \mathrm{C}$, indicating a good heat resistance even at temperature as high as $140^{\circ} \mathrm{C}$.

To show the enhancement in heat resistance of the annealed samples directly, the two ends of straight sample bars obtained by compression molding were fixed and a $50 \mathrm{~g}$ weight was hung in the middle of the sample bars. The photos of the samples after placing in an $80^{\circ} \mathrm{C}$ oven for $5 \mathrm{~min}$ were taken to show the heat resistance of the samples at high temperature. The photos after test are shown in Fig. 11c and $c^{\prime}$. It is obvious that all the meltquenched samples show serious deformation. While the annealed samples show much better heat resistance with limited deformation, and the ternary blends show better dimension stability than the binary blends, in agreement with the difference in the $E^{\prime}$ of the annealed sample at $80^{\circ} \mathrm{C}$.

\section{CONCLUSIONS}

In summary, we successfully fabricated highly toughened and heat-resistant PLLA ternary blends by peroxide-induced dynamic vulcanization with PDLA and an unsaturated bioelastomer. During melt processing, SC crystallites were formed by the cocrystallization of PLLA and PDLA. On the one hand, SC crystallites increased the matrix molecular entanglement, which improved the toughness of brittle PLLA with low molecular entanglement. On the other hand, increase in the matrix molecular entanglement increased the melt viscosity of the matrix and then enhanced phase separation of the blends, which was detrimental to improvement of the toughness of the blends. Therefore, the toughness of the PLLA/ VUB/PDLA blend first increased and then decreased with increase in the content of PDLA. The ternary blend with 10 wt.\% PDLA showed the highest impact strength. Furthermore, SC crystallites were highly efficient nucleating agents for PLLA, which remarkably accelerated the crystallization rates of PLLA and enabled the fabrication of heat-resistant PLLA blends with highly crystalline matrix in a short time using a conventional injection molding technique. Although the toughness decreased on the construction of a highly crystalline matrix, it was acceptable since the heat resistance was enhanced remarkably, which would enhance the durability and dimensional stability of PLLA-based materials to expand its applications to durable products. We believe that constructing SC crystallites during dynamic vulcanization of PLLA with a bio-based rubbery polymer provides a powerful way to produce high-performance and fully 

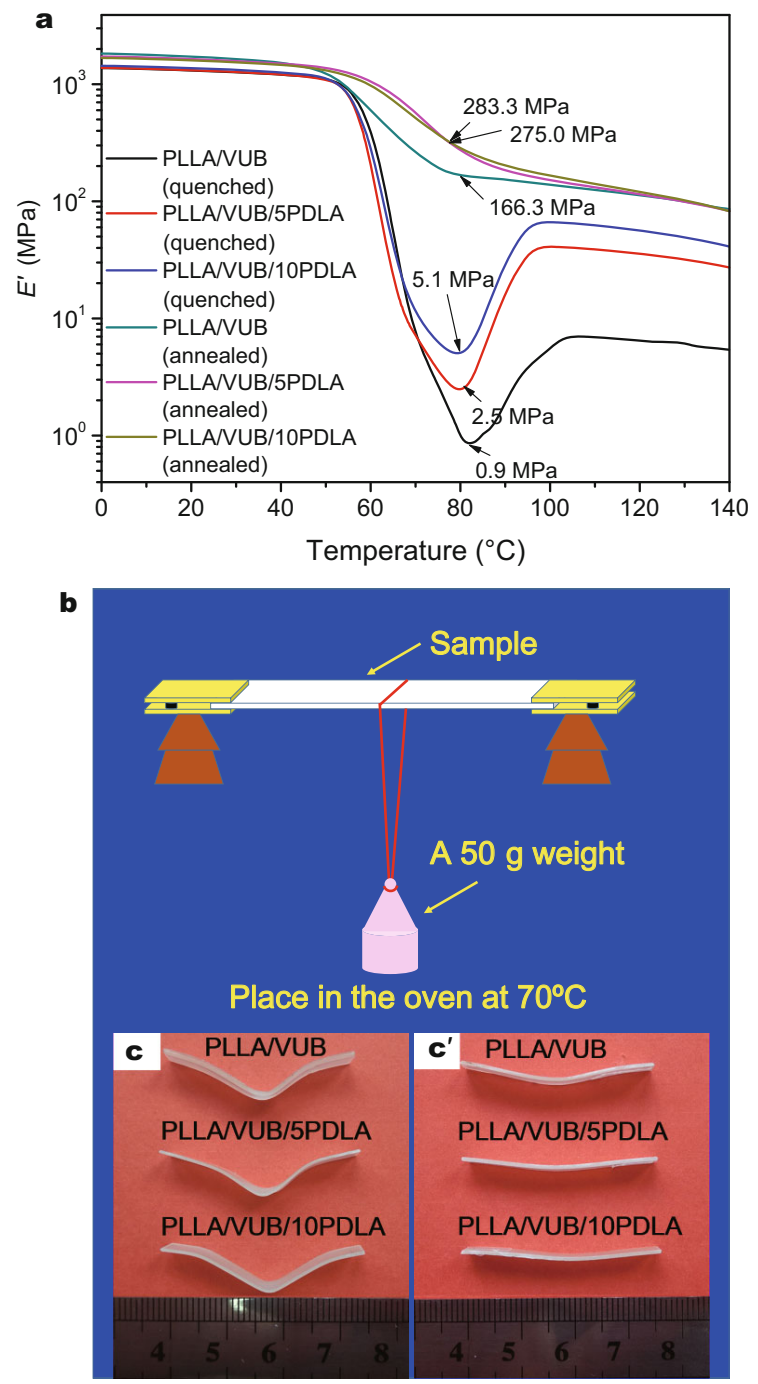

Figure 11 (a) Storage modulus versus temperature for representative regular and annealed injection molded samples, (b) schematic illustration of the designed heat resistance measurement, and the photos after measurement for regular (c) and annealed $\left(c^{\prime}\right)$ injection molded samples.

sustainable PLLA materials with high toughness and excellent heat resistance.

Received 2 August 2017; accepted 7 September 2017; published online 28 September 2017

1 Zhu Y, Romain C, Williams CK. Sustainable polymers from renewable resources. Nature, 2016, 540: 354-362

2 Liu Y, Zheng Y, Hayes B. Degradable, absorbable or resorbablewhat is the best grammatical modifier for an implant that is eventually absorbed by the body? Sci China Mater, 2017, 60: 377391

3 Nagarajan V, Mohanty AK, Misra M. Perspective on polylactic acid (PLA) based sustainable materials for durable applications: focus on toughness and heat resistance. ACS Sustain Chem Eng, 2016, 4:
2899-2916

4 Tan BH, Muiruri JK, Li Z, et al. Recent progress in using stereocomplexation for enhancement of thermal and mechanical property of polylactide. ACS Sustain Chem Eng, 2016, 4: 5370-5391

5 Zhang L, Li Y, Wang H, et al. Strong and ductile poly(lactic acid) nanocomposite films reinforced with alkylated graphene nanosheets. Chem Eng J, 2015, 264: 538-546

6 Liu H, Zhang J. Research progress in toughening modification of poly(lactic acid). J Polym Sci B Polym Phys, 2011, 49: 1051-1083

7 Zolali AM, Heshmati V, Favis BD. Ultratough co-continuous PLA/ PA11 by interfacially percolated poly(ether- $b$-amide). Macromolecules, 2017, 50: 264-274

8 Shi Y, Li M, Wang N, et al. Para-amino benzoic acid doped microgrooved carbon fibers to improve strength and biocompatibility of PLA-PEG. Sci China Mater, 2016, 59: 911-920

9 Lebarbé T, Grau E, Gadenne B, et al. Synthesis of fatty acid-based polyesters and their blends with poly(L-lactide) as a way to tailor PLLA toughness. ACS Sustain Chem Eng, 2015, 3: 283-292

10 Hao X, Kaschta J, Liu X, et al. Entanglement network formed in miscible PLA/PMMA blends and its role in rheological and thermo-mechanical properties of the blends. Polymer, 2015, 80: 38-45

11 Sun Y, Yang L, Lu X, et al. Biodegradable and renewable poly (lactide)-lignin composites: synthesis, interface and toughening mechanism. J Mater Chem A, 2015, 3: 3699-3709

12 Ojijo V, Ray SS. Super toughened biodegradable polylactide blends with non-linear copolymer interfacial architecture obtained via facile in-situ reactive compatibilization. Polymer, 2015, 80: 1-17

13 Liu GC, He YS, Zeng JB, et al. In situ formed crosslinked polyurethane toughened polylactide. Polym Chem, 2014, 5: 2530-2539

14 Hassouna F, Raquez JM, Addiego F, et al. New development on plasticized poly(lactide): Chemical grafting of citrate on PLA by reactive extrusion. Eur Polymer J, 2012, 48: 404-415

15 Zeng JB, Li YD, Zhu QY, et al. A novel biodegradable multiblock poly(ester urethane) containing poly(l-lactic acid) and poly(butylene succinate) blocks. Polymer, 2009, 50: 1178-1186

16 Anderson K, Schreck K, Hillmyer M. Toughening polylactide. Polymer Revs, 2008, 48: 85-108

17 Zeng JB, Li KA, Du AK. Compatibilization strategies in poly(lactic acid)-based blends. RSC Adv, 2015, 5: 32546-32565

18 Imre B, Pukánszky B. Compatibilization in bio-based and biodegradable polymer blends. Eur Polymer J, 2013, 49: 1215-1233

19 Liu H, Song W, Chen F, et al. Interaction of microstructure and interfacial adhesion on impact performance of polylactide (PLA) ternary blends. Macromolecules, 2011, 44: 1513-1522

20 Zhao TH, Wu Y, Li YD, et al. High performance and thermal processable dicarboxylic acid cured epoxidized plant oil resins through dynamic vulcanization with poly(lactic acid). ACS Sustain Chem Eng, 2017, 5: 1938-1947

21 Zhao TH, He Y, Li YD, et al. Dynamic vulcanization of castor oil in a polylactide matrix for toughening. RSC Adv, 2016, 6: 7954279553

22 Wang Y, Chen K, Xu C, et al. Supertoughened biobased poly(lactic acid)-epoxidized natural rubber thermoplastic vulcanizates: fabrication, co-continuous phase structure, interfacial in situ compatibilization, and toughening mechanism. J Phys Chem B, 2015, 119: 12138-12146

23 Yuan D, Chen Z, Xu C, et al. Fully biobased shape memory material based on novel cocontinuous structure in poly(lactic acid)/ natural rubber TPVs fabricated via peroxide-induced dynamic vulcanization and in situ interfacial compatibilization. ACS Sustain 
Chem Eng, 2015, 3: 2856-2865

24 Chen Y, Yuan D, Xu C. Dynamically vulcanized biobased polylactide/natural rubber blend material with continuous cross-linked rubber phase. ACS Appl Mater Interfaces, 2014, 6: 3811-3816

25 Liu H, Chen F, Liu B, et al. Super toughened poly(lactic acid) ternary blends by simultaneous dynamic vulcanization and interfacial compatibilization. Macromolecules, 2010, 43: 6058-6066

26 Zhang K, Nagarajan V, Misra M, et al. Supertoughened renewable PLA reactive multiphase blends system: phase morphology and performance. ACS Appl Mater Interfaces, 2014, 6: 12436-12448

27 Li X, Kang H, Shen J, et al. Highly toughened polylactide with novel sliding graft copolymer by in situ reactive compatibilization, crosslinking and chain extension. Polymer, 2014, 55: 4313-4323

28 Fang H, Jiang F, Wu Q, et al. Supertough polylactide materials prepared through in situ reactive blending with peg-based diacrylate monomer. ACS Appl Mater Interfaces, 2014, 6: 1355213563

29 Song W, Liu H, Chen F, et al. Effects of ionomer characteristics on reactions and properties of poly(lactic acid) ternary blends prepared by reactive blending. Polymer, 2012, 53: 2476-2484

30 Liu GC, He YS, Zeng JB, et al. Fully biobased and supertough polylactide-based thermoplastic vulcanizates fabricated by peroxide-induced dynamic vulcanization and interfacial compatibilization. Biomacromolecules, 2014, 15: 4260-4271

31 Odent J, Raquez JM, Duquesne E, et al. Random aliphatic copolyesters as new biodegradable impact modifiers for polylactide materials. Eur Polymer J, 2012, 48: 331-340

32 Guo X, Zhang J, Huang J. Poly(lactic acid)/polyoxymethylene blends: morphology, crystallization, rheology, and thermal mechanical properties. Polymer, 2015, 69: 103-109

33 Han Q, Wang Y, Shao C, et al. Nonisothermal crystallization kinetics of biodegradable poly(lactic acid)/zinc phenylphosphonate composites. J Composite Mater, 2014, 48: 2737-2746

34 Tang Z, Zhang C, Liu X, et al. The crystallization behavior and mechanical properties of polylactic acid in the presence of a crystal nucleating agent. J Appl Polym Sci, 2012, 125: 1108-1115

35 Yin HY, Wei XF, Bao RY, et al. Enhancing thermomechanical properties and heat distortion resistance of poly(L-lactide) with high crystallinity under high cooling rate. ACS Sustain Chem Eng, 2015, 3: 654-661

36 Srithep Y, Nealey P, Turng LS. Effects of annealing time and temperature on the crystallinity and heat resistance behavior of injection-molded poly(lactic acid). Polym Eng Sci, 2013, 53: 580588

37 Yin HY, Wei XF, Bao RY, et al. High-melting-point crystals of poly (L-lactic acid) (PLLA): the most efficient nucleating agent to enhance the crystallization of PLLA. CrystEngComm, 2015, 17: 2310-2320

38 Yu F, Liu T, Zhao X, et al. Effects of talc on the mechanical and thermal properties of polylactide. J Appl Polym Sci, 2012, 125: E99-E109

39 Xu Z, Niu Y, Yang L, et al. Morphology, rheology and crystallization behavior of polylactide composites prepared through addition of five-armed star polylactide grafted multiwalled carbon nanotubes. Polymer, 2010, 51: 730-737

40 Tsuji H, Takai H, Saha SK. Isothermal and non-isothermal crystallization behavior of poly(l-lactic acid): effects of stereocomplex as nucleating agent. Polymer, 2006, 47: 3826-3837

41 Krikorian V, Pochan DJ. Unusual crystallization behavior of organoclay reinforced poly(L-lactic acid) nanocomposites. Macro- molecules, 2004, 37: 6480-6491

42 Nam JY, Sinha Ray S, Okamoto M. Crystallization behavior and morphology of biodegradable polylactide/layered silicate nanocomposite. Macromolecules, 2003, 36: 7126-7131

43 Tsuji H, Takai H, Fukuda N, et al. Non-isothermal crystallization behavior of poly(L-lactic acid) in the presence of various additives. Macromol Mater Eng, 2006, 291: 325-335

44 Wei XF, Bao RY, Cao ZQ, et al. Stereocomplex crystallite network in asymmetric PLLA/PDLA blends: formation, structure, and confining effect on the crystallization rate of homocrystallites. Macromolecules, 2014, 47: 1439-1448

45 Saeidlou S, Huneault MA, Li H, et al. Poly(lactic acid) stereocomplex formation: application to PLA rheological property modification. J Appl Polym Sci, 2014, 131

46 Zhang K, Yu HO, Shi YD, et al. Morphological regulation improved electrical conductivity and electromagnetic interference shielding in poly(L-lactide)/poly( $\varepsilon$-caprolactone)/carbon nanotube nanocomposites via constructing stereocomplex crystallites. J Mater Chem C, 2017, 5: 2807-2817

47 Wang $\mathrm{M}, \mathrm{Wu} \mathrm{Y}, \mathrm{Li} \mathrm{YD}$, et al. Progress in toughening poly(lactic acid) with renewable polymers. Polymer Rev, 2017, 57: 557-593

48 Liu Z, Luo Y, Bai H, et al. Remarkably enhanced impact toughness and heat resistance of poly(L-lactide)/thermoplastic polyurethane blends by constructing stereocomplex crystallites in the matrix. ACS Sustain Chem Eng, 2016, 4: 111-120

49 Lin L, Deng C, Lin GP, et al. Super toughened and high heatresistant poly(lactic acid) (PLA)-based blends by enhancing interfacial bonding and PLA phase crystallization. Ind Eng Chem Res, 2015, 54: 5643-5655

50 Signori F, Coltelli MB, Bronco S. Thermal degradation of poly (lactic acid) (PLA) and poly(butylene adipate-co-terephthalate) (PBAT) and their blends upon melt processing. Polymer Degradation Stability, 2009, 94: 74-82

51 Lin S, Yu W, Wang X, et al. Study on the thermal degradation kinetics of biodegradable poly(propylene carbonate) during melt processing by population balance model and rheology. Ind Eng Chem Res, 2014, 53: 18411-18419

52 Gupta A, Simmons W, Schueneman GT, et al. Rheological and thermo-mechanical properties of poly(lactic acid)/lignin-coated cellulose nanocrystal composites. ACS Sustain Chem Eng, 2017, 5: $1711-1720$

53 Bai J, Wang J, Wang W, et al. Stereocomplex crystallite-assisted shear-induced crystallization kinetics at a high temperature for asymmetric biodegradable PLLA/PDLA blends. ACS Sustain Chem Eng, 2016, 4: 273-283

54 Tsuji H. Poly(lactide) stereocomplexes: formation, structure, properties, degradation, and applications. Macromol Biosci, 2005, 5: $569-597$

55 Sakai F, Nishikawa K, Inoue Y, et al. Nucleation enhancement effect in poly(L-lactide) (PLLA)/poly( $\varepsilon$-caprolactone) (PCL) blend induced by locally activated chain mobility resulting from limited miscibility. Macromolecules, 2009, 42: 8335-8342

56 Han L, Xie Q, Bao J, et al. Click chemistry synthesis, stereocomplex formation, and enhanced thermal properties of well-defined poly (L-lactic acid)- $b$-poly(D-lactic acid) stereo diblock copolymers. Polym Chem, 2017, 8: 1006-1016

57 Bai H, Huang C, Xiu H, et al. Toughening of poly(l-lactide) with poly( $\varepsilon$-caprolactone): Combined effects of matrix crystallization and impact modifier particle size. Polymer, 2013, 54: 5257-5266

58 Bai H, Xiu H, Gao J, et al. Tailoring impact toughness of poly(L- 
lactide)/poly(e-caprolactone) (PLLA/PCL) blends by controlling crystallization of PLLA matrix. ACS Appl Mater Interfaces, 2012, 4: 897-905

59 Zhu LD, Yang HY, Cai GD, et al. Submicrometer-sized rubber particles as "craze-bridge" for toughening polystyrene/high-impact polystyrene. J Appl Polym Sci, 2013, 129: 224-229

Acknowledgements This work was supported by the National Science Foundation of China (51673158), the Opening Project of Key Laboratory of Polymer Processing Engineering (South China University of Technology), Ministry of Education (KFKT02), and the Fundamental
Research Funds for the Central Universities (XDJK2017A016 and XDJK2017C022).

Author contributions Si WJ and An XP carried out the experiments, analyzed the data and wrote the draft of manuscript; Zeng JB and Chen YK proposed the project and critical comments on the writing of the manuscript; Wang YZ provided some additional suggestions and comments on the design and writing of the manuscript. All the authors checked and approved the manuscript.

Conflict of interest The authors declare that they have no conflict of interest.

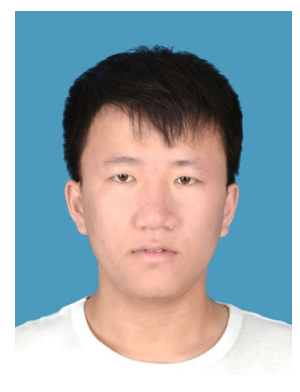

Wan-Jie $\mathbf{S i}$ is a postgraduate student majoring in polymer chemistry and physics at Southwest University and his research project is high-performance modification of poly(lactic acid).

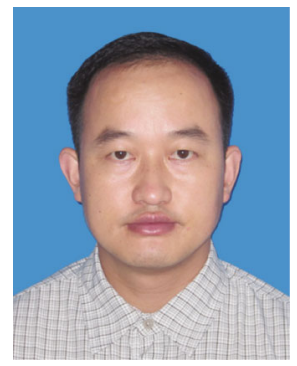

Jian-Bing Zeng received his $\mathrm{PhD}$ degree in 2009 from Sichuan University under the supervision of Prof. Yu-Zhong Wang. He worked as a lecturer and associate professor at Sichuan University (2009-2014) and has been working as a professor at southwest university since 2014. His research interests focus on biobased/biodegradable polymers and high performance reprocessible polymer networks.

\section{通过动态硫化制备的全生物基、高韧性与高耐热聚乳酸三元共混物}

司万㷊 ${ }^{1}$, 安许沛 $^{1}$, 曾建兵 ${ }^{1,2^{*}}$, 陈玉坤 ${ }^{2}$, 王玉忠 ${ }^{3}$

摘要 随着环境污染的加剧以及不可再生石油资源的逐渐枯竭, 生物基高分子材料受到了越来越多的关注. 聚乳酸 作为一种可再生的高 分子材料, 由于具有良好的生物降解性、生物相容性和机械强度, 在众多领域都具有巨大应用潜力. 然而聚乳酸也存在一些缺陷限制着它 的应用领域, 如冲击韧性差、耐热形变温度低等. 基于此, 我们利用动态硫化技术, 将左旋聚乳酸(PLLA), 右旋聚乳酸(PDLA) 以及不饱和 生物基弹性体 (UBE)通过自由基引发动态硫化成功制备了冲击韧性优于高抗冲聚苯乙烯、耐热性突出的全生物基PLLA/VUB/PDLA三元 共混物, 在不降低生物质含量、不影响其降解性能的情况下, 实现了 PLLA的高性能化. 